\title{
PERANCANGAN APLIKASI CUTI KARYAWAN PADA PT LOTTE MART INDONESIA BERBASIS JAVA NETBEANS
}

\author{
Ajeng Rachmawati ${ }^{1}$, Ulfa Pauziah ${ }^{2}$, Maria Cleopatra ${ }^{3}$ \\ 1,2,3 Teknik Informatika Fakultas Teknik dan Ilmu Komputer, Universitas Indraprasta PGRI \\ Jalan Raya Tengah No 80, Kelurahan Gedong, Pasar Rebo, Jakarta Timur \\ 19ajengrachmawati22@gmail.com, ${ }^{2}$ ulfapauziah9@gmail.com, ${ }^{3}$ mariacleopatra1313@gmail.com
}

\begin{abstract}
ABSTRAK
Teknologi dapat membuat pekerjaan menjadi lebih efisien. Permasalahan yang terdapat pada PT. Lotte Mart Indonesia adalah pengolahan data yang masih menggunakan cara manual menyebabkan lambatnya pengolahan data yang tidak terstruktur. Untuk mengatasi kelambatan dan keakuratan data, sistem informasi pengolahan data dapat dirancang dengan menggunakan bahasa pemrograman Java dan database MySQL. Penelitian ini bertujuan untuk mempermudah sistem pendataan yang terkomputerisasi dalam mengelola data cuti karyawan. Metode penelitian yang digunakan adalah penelitian dan pengembangan (R\&D), yaitu metode penelitian yang digunakan untuk menghasilkan produk tertentu dan memuji keefektifan produk tersebut. Saya membangun sistem ini menggunakan alat perancangan sistem, database bahasa MySQL, XAMPP dengan Data Flow Diagram (DAD), Nol dan Detail. Berdasarkan penelitian ini, dari hasil berupa aplikasi yang dibuat dapat mempermudah proses pendataan. Sistem yang ada pada aplikasi cuti karyawan sudah terkomputerisasi, efisien dalam penyimpanan data dan laporan.
\end{abstract}

Kata Kunci: Sistem Informasi, Cuti Karyawan, Netbeans

\begin{abstract}
Technology can make work more efficient. The problems that exist in PT. Lotte Mart Indonesia is a data processing is still using the manual method, which causes slow processing of unstructured data. An overcome slowness and data accuracy, the leaved data management information system is designed using the Java programming language and MySQL database. This research aims to facilitate the data collection system being computerized in managing employee leave data. The research method used is research and development $(R \&$ $R \& D)$, namely research methods used to produce specific products and praise the product's effectiveness. I am building this system using a system design tool, the MySQL language database, XAMPP with Data Flow Diagrams (DAD), Zero and Details. Based on this research from the results of application created can simplify the process of data collection. The existing system in the employee leave application is computerized, efficient in data storage and reports.
\end{abstract}

Key Word: Information Systems, Employee Leave, Netbeans

\section{PENDAHULUAN}

Cuti salah satu hak karyawan perusahaan. Cuti digunakan oleh karyawan untuk tidak masuk kerja karena sakit, refresing, melahirkan, atau kebutuhan lainnya, sesuai dengan ketentuan cuti pada setiap organisasi. Dengan pesatnya perkembangan teknologi, informasi digunakan sebagai sarana untuk meningkatan informasi. Penggunaan ini akan memudahkan pekerjaan seperti memproses data lebih cepat, membuat keputusan yang lebih akurat, dan menghemat waktu dan biaya. Selain itu, informasi yang tersedia untuk pengguna internet yang semakin lama semakin luas. Dengan menggunaan sistem komputerisasi untuk meningkatkan keakuratan penyajian data.
PT. Lotte Mart indonesia adalah perusahaan yang beroperasi diperkulakan atau grosir (Wholesale). Dimana pemrosesan datanya kurang efisien untuk pengajuan cuti karyawan dan pembuatan laporan cuti karyawan masih menggunakan Microsoft Exel. Masalah yang muncul adalah kesulitan dalam mengolah data cuti karena pengolahan data cuti yang masih manual. Pencatatan yang dilakukan masih seadanya Permasalahan yang muncul adalah dalam penyusunan laporan cuti bulanan dan cuti tahunan.

Berdasarkan latar belakang maka penulis mengangkat masalah tentang pembuatan sebuah data yang disimpan dalam suatu database sebagai laporan yang berjudul "Perancangan sistem informasi cuti karyawan berbasis java netbeans pada PT. Lotte Mart 
Indonesia". Aplikasi ini dikembangkan memanfaatkan teknologi informasi berbasis java, yaitu menggunakan Java Netbeans sebagai bahasa pemrograman dan menggunakan mysql untuk pengolahan database.

Menurut (Syifaun Nafisah 2003) perancangan adalah penggambaran, perencanaan dan pembuatan sketsa atau pengaturan dari beberapa elemen yang terpisah ke dalam satu kesatuan yang utuh dan berfungsi Perancangan sistem dapat dirancang dalam bentuk bagan alir sistem (system flowchart), yang merupakan alat bentuk grafik yang dapat digunakan untuk menunjukan urutan-urutan proses dari sistem.

Perancangan sistem adalah perancangan dalam pembangunan perangat lunak merupakan upaya untuk mengkonstruksi sebuah sistem yang memberikan kepuasan (mungkin informal) akan spesifikasi kebutuhan fungsional, memenuhi target, memenuhi kebutuhan secara implisit atau eksplisit dari segi perfomansi maupun penggunaan sumber daya kepuasan batasan pada proses desain dari segi biaya, waktu, dan perangkat (Rosa dan M 2013).

Menurut (Jogiyanto 2005) sistem adalah kumpulan dari elemen-elemen yang berinteraksi untuk mencapai suatu tujuan tertentu. Suatu sistem dapat terdiri dari sistemsistem bagian (subsistem) yang saling berinteraksi sebagai akibat adanya input yang diproses menjadi output/informasi.

Menurut (Muslihudin dan Oktafianto 2016) informasi merupakan hasil pengolahan data, sehingga menjadi bentuk yang penting bagi penerimanya dan mempunyai kegunaan sebagai dasar dalam pengambilan keputusan yang dapat dirasakan akibatnya secara langsung saat itu juga atau secara tidak langsung pada saat mendatang.

Menurut (Sutarman 2021) Sistem informasi adalah sistem dapat didefinisikan dengan mengumpulkan, memproses, menyimpan, menganalisis, menyebarkan informasi untuk tujuan tertentu. Seperti sistem lainnya, sebuah sistem informasi terdiri atas input (data, instruksi) dan output (laporan, kalkulasi).
Cuti merupakan salah satu hak pegawai dalam suatu instansi atau perusahaan. Cuti dapat diguankan oleh pegawai untuk tiidak masuk kerja dengan alasan tertentu, misalnya refreshing, istirahat sakit, melahirkan, menunaikan kewajiban agama, dan keperluan lain sesuai dengan ketentuan cuti pada masing-masing organisasi. Cuti adalah keadaan tidak masuk kerja yang diijinkan dalam jangka waktu tertentu (Djatmika 1990).

Menurut undang-undang nomor 13 tahun 2003 tentang ketenagakerjaan pasal 1 ayat 2 menyebutkan bahwa karyawan/tenaga kerja adalah setiap orang yang mampu melakukan pekerjaan guna menghasilkan barang dan jasa baik untuk memenuhi kebutuhan sendiri maupun untuk masyarakat, baik didalam maupun diluar hubungan kerja.

Netbeans adalah Integrated Development Environment (IDE) berbasiskan Java dari Sun Microsystems yang berjalan di atas Swing.Swing merupakan sebuah teknologi Java untuk pengembangan aplikasi desktop yang dapat berjalan di berbagai macam platfroms, seperti Windows, Linux, Mac OS X, and Solaris (Bay Haqi 2019).

Xampp adalah perangkat lunak bebass (free software) yang mendukung banyak sistem operasi, merupakan kompilasi dari beberapa program. Fungsi XAMPP sendiri sebagai server yang berdiri sendiri (localhost), yang terdiri dari beberapa program, antara lain: Appache HTTP Server, MySQL database, dan penerjemah bahasa yang ditulis dengan pemrograman PHP dan Perl (Bay Haqi 2019).

MYSQL adalah untuk mengembangkan aplikasi web pada client. MYSQL dikembangkan pada tahun 1994 oleh sebuah perusahaan pengembang software dan konsultan database di Swdia bernama TcX Data Consult AB (Bay Haqi 2019).

Menurut (Elfi Husda dan Wangdra 2016) ERD adalah model konsepsual yg endeskripsikan hubungan antara penyimpanan (dalam DFD). ERD digunakan untuk memodelkan struktur data hubungan antar data. 


\section{METODE PENELITIAN}

Waktu penelitian yang dilakukan selama empat bulan dimulai dari bulan Maret 2021 sampai dengan bulan Juli.

Metode penelitian yang digunakan adalah penelitian dan pengembangan $(R \& D)$ yaitu metode penelitian yang digunakan untuk menghasilkan produk tertentu dan memuji keefektifan produk (Sugiyono 2016). Menurut (Putra 2017) Research and Development (R\&D) merupakan metode penelitian secara sengaja, sistematis, untuk menemukan, memperbaiki, mengembangkan, menghasilkan, maupun menguji keefektifan produk, efektif, efisien, produkti, dan bermakna.

Metode pengumpulan:

1. Observasi: pengumpulan data dilakukan dengan cara pengamatan langsung di tempat penelitian.

2. Wawancara: penelitian ini menggunakan wawancara langsung dengan General Manager perusahaan PT. Lotte Mart Indonesia untuk mengetahui sistem pengajuan cuti yang sedang berjalan serta kendala-kendala yang menghambat dalam proses pengajuan cuti.

3. Study kepustakaan dilakukan dengan mengumpulkan data dan informasi dari kutipan-kutipan buku, serta beberapa hasil penelitian yang berkaitan.

\section{HASIL DAN PEMBAHASAN}

Perancangan Sistem Informasi Cuti Karyawan Berbasis Java Netbeans pada PT Lotte Mart Indonesia yang terkomputerisasi sehingga dapat dihasilkan informasi yang lebih cepat, tepat dan akurat:

1. Membangun sistem informasi yang sudah terkomputerisasi yang dapat membantu kinerja admin dalam pendataan karyawan, jabatan, cuti, pengajuan cuti, dan pembuatan laporan.

2. Perancangan sistem database untuk menyimpan data menjadi lebih efisien, lebih akurat, dan lebih sedikit risiko kehilangan data.

3. Pembuatan sistem informasi yang dapat dimengerti oleh semua pihak PT Lotte Mart Indonesia
Dekomposisi $\quad$ Fungsi Sistem yang Diusulkan

Dekomposisi fungsi dimaksudkan untuk mengetahui gambaran fungsi-fungsi proses dan bentuk masukan serta keluaran yang terdapat pada sistem yang akan dijalankan. Berikut ini merupakan penggambaran tentang sistem yang diusulkan pada perancangan sistem informasi cuti karyawan pada PT. Lotte Mart Indonesia secara keseluruhan dalam diagram konteks, diagram nol, ERD:

\section{Diagram Konteks Sistem Usulan}

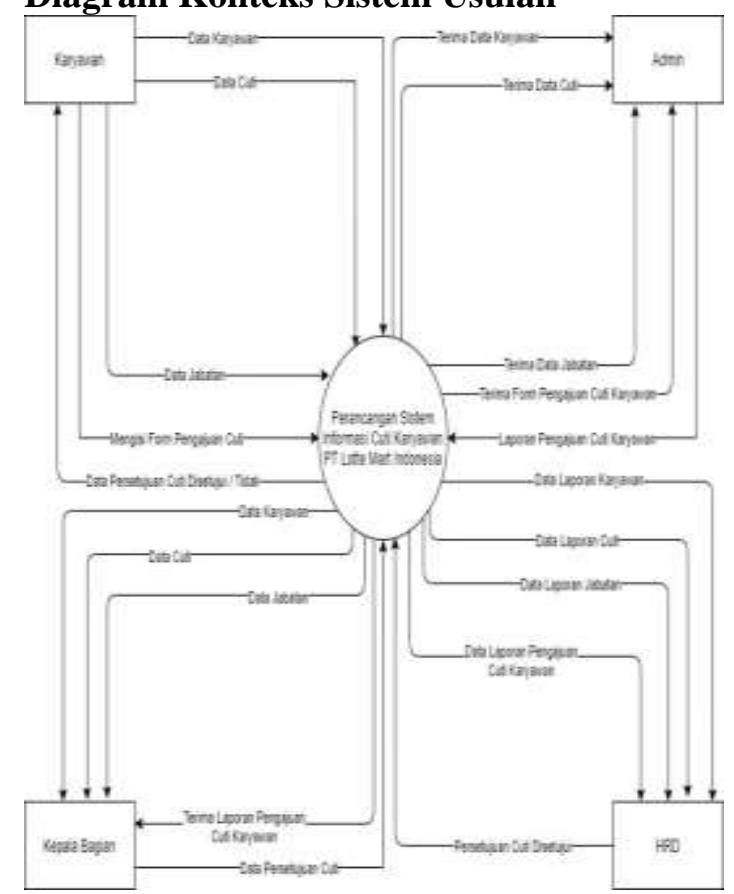

Gambar 1. Diagram Konteks Sistem Usulan

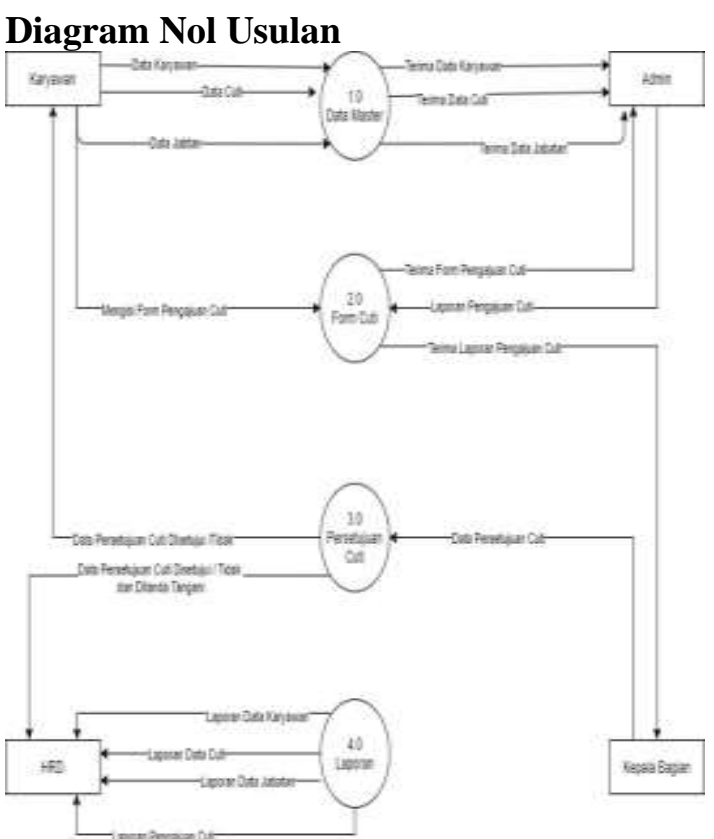

Gambar 2. Diagram Nol Usulan 


\section{Entity Relationship Diagram (ERD)}

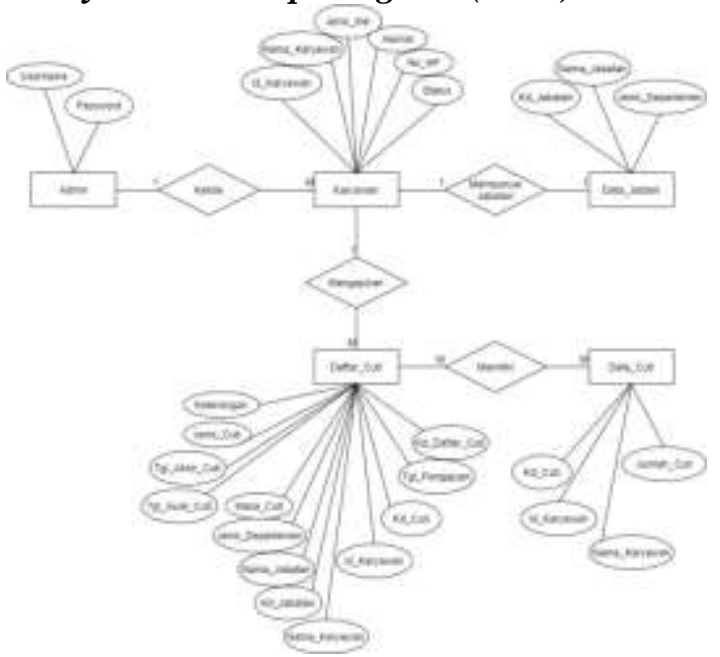

Gambar 3. Entity Relationship Diagram (ERD)

\section{Tampilan Layar Daftar Admin}

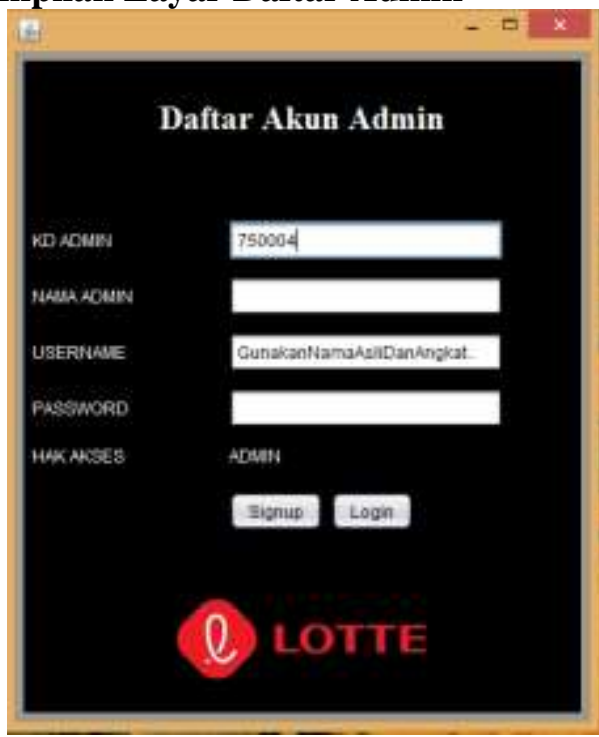

Gambar 4. Tampilan Layar Daftar Admin

Daftar Admin digunakan sebagai kata kunci sebelum masuk ke login admin. Menu ini untuk akses admin ke menu login admin.

\section{Tampilan Layar Login Admin}

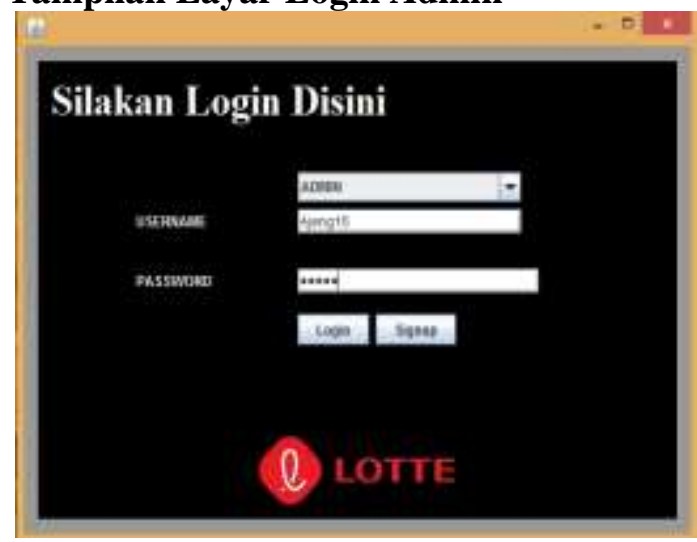

Gambar 5. Tampilan Layar Login Admin
Menu Login Admin digunakan sebelum admin memasuki program utama. Menu ini bertujuan untuk mengamankan program agar tidak dapat diakses oleh semua orang kecuali admin.

\section{Tampilan Layar Login HRD}

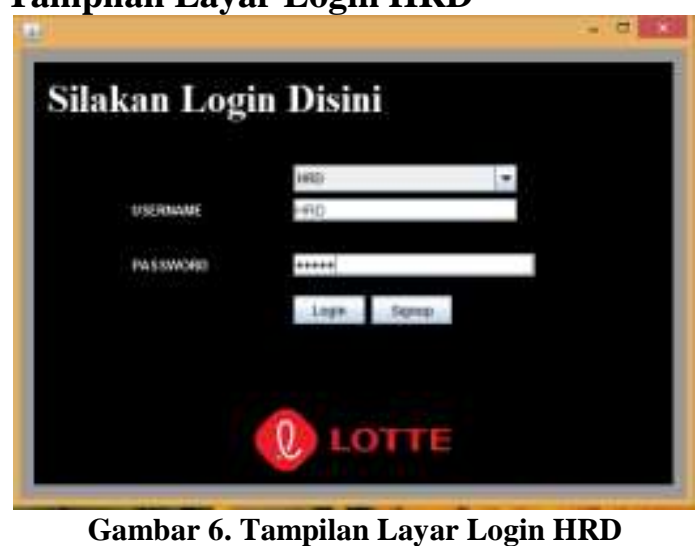

Menu Login HRD digunakan sebelum HRD masuk ke program utama. Menu ini bertujuan untuk mengamankan program agar semua orang tidak dapat masuk kecuali HRD.

\section{Tampilan Layar Halaman Utama Admin}

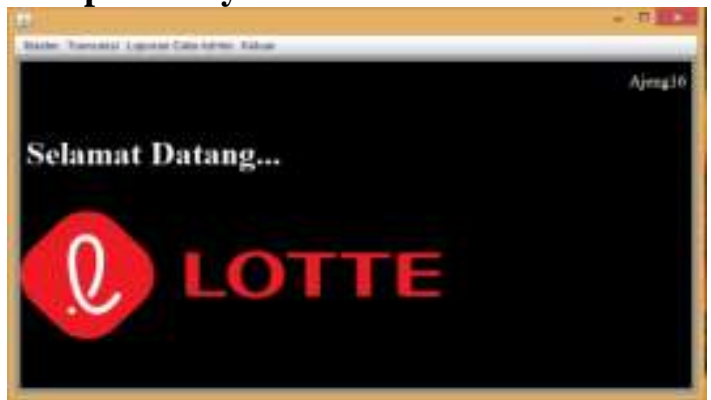

Gambar 7. Tampilan Layar Halaman Utama Admin

Menu diatas menampilkan tampilan menu utama sistem informasi cuti karyawan. Menu ini berfungsi untuk memasukkan data-data yang berkaitan dengan Data Karyawan, Data Jabatan, Data Cuti, dan Data Pengajuan Cuti.

\section{Tampilan Layar Halaman Utama HRD}

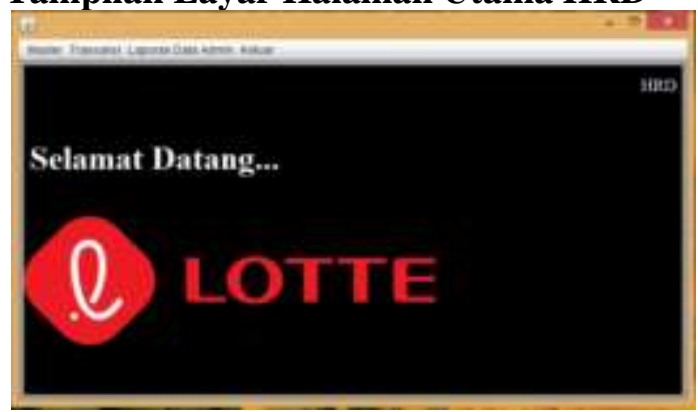

Gambar 8. Tampilan Layar Halaman Utama HRD

677 | Perancangan Aplikasi Cuti Karyawan pada PT Lotte Mart Indonesia Berbasis Java Netbeans 
Menu diatas menampilkan tampilan menu utama sistem informasi cuti karyawan. Menu ini digunakan untuk melihat data yang berkaitan dengan Data Karyawan, Data Jabatan, Data Cuti, dan Data Pengajuan Cuti.

\section{Tampilan Layar Data Karyawan}

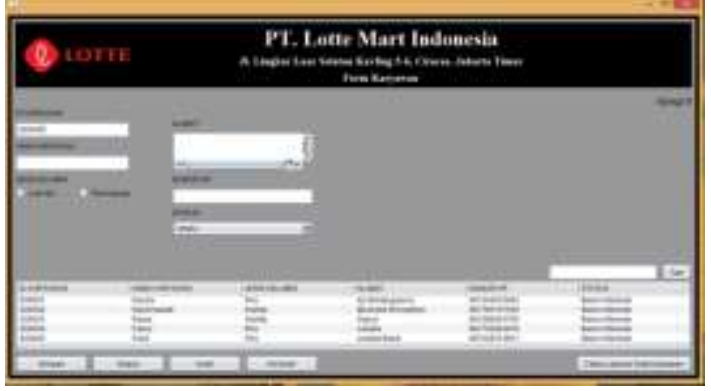

Gambar 9. Tampilan Layar Data Karyawan

Tampilan ini admin dapat mengolah data untuk menyimpan Data Karyawan tersebut, siapa saja yang sudah mulai bekerja dan sudah resmi menjadi karyawan di PT Lotte Mart Indonesia.

\section{Tampilan Layar Data Jabatan}

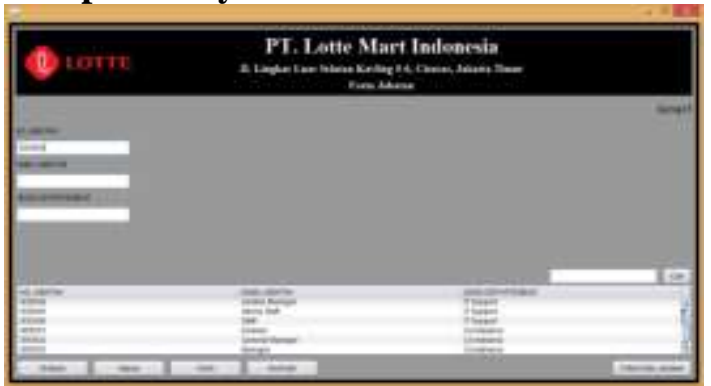

Gambar 10. Tampilan Layar Data Jabatan

Pada tampilan ini admin dapat mengolah data untuk menyimpan Data Jabatan tersebut. Melakukan perubahan Data Jabatan dan dapat menghapus Data Jabatan.

\section{Tampilan Layar Data Cuti}

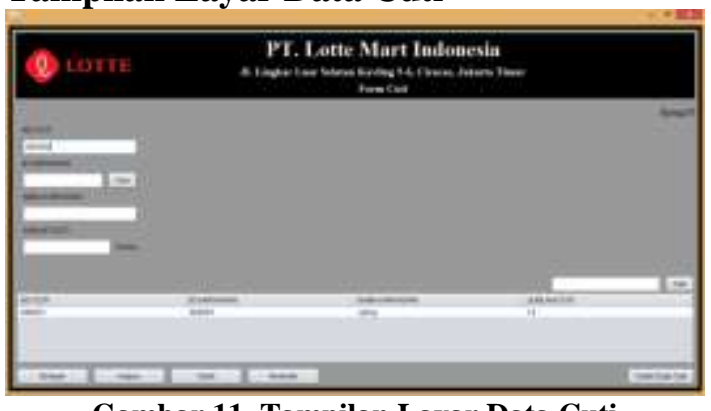

Gambar 11. Tampilan Layar Data Cuti

Pada tampilan ini admin dapat meng-input Data Cuti. Melakukan penginputan cuti dan dapat menghapus Data Cuti
Tampilan Layar Pengajuan Cuti

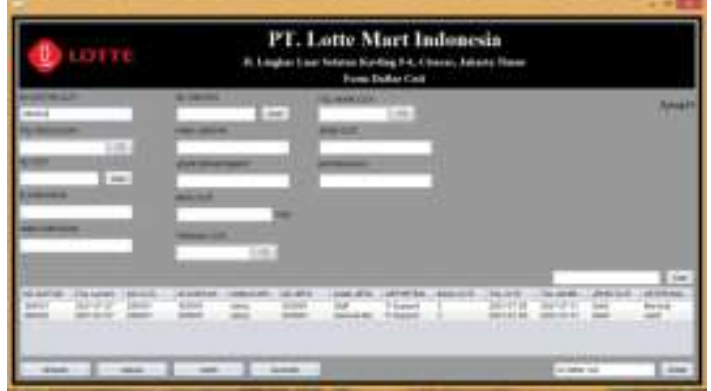

Gambar 12. Tampilan Layar Pengajuan Cuti

Pada tampilan ini admin dapat mengolah data untuk menyimpan data cuti tersebut dan dapat diubah ataupun dihapus didalam database cuti jika ada data baru maupun perusahan.

\section{Tampilan layar Laporan Data Karyawan}

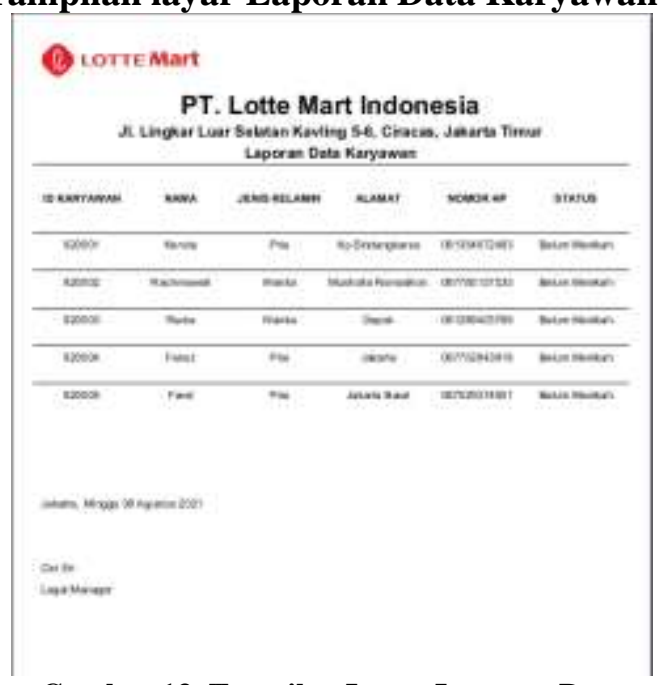

Gambar 13. Tampilan Layar Laporan Data Karyawan

Tampilan ini admin dapat memberikan Laporan Data Karyawan kepada atasan atau HRD setelah melakukan input data karyawan dan dapat dilakukan percetakan baik cetak harian maupun bulanan.

Tampilan Layar Laporan Data Jabatan

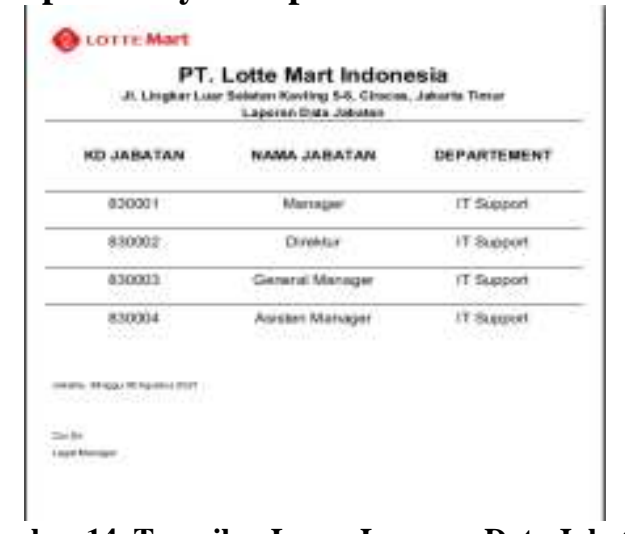

Gambar 14. Tampilan Layar Laporan Data Jabatan 
Tampilan ini admin dapat memberikan Laporan Data Jabatan kepada atasan atau HRD yang telah tersimpan, setalah melakukan input data jabatan dan dapat dilakukan percetakan baik cetak harian maupun bulanan.

\section{Tampilan Layar Laporan Data Cuti}

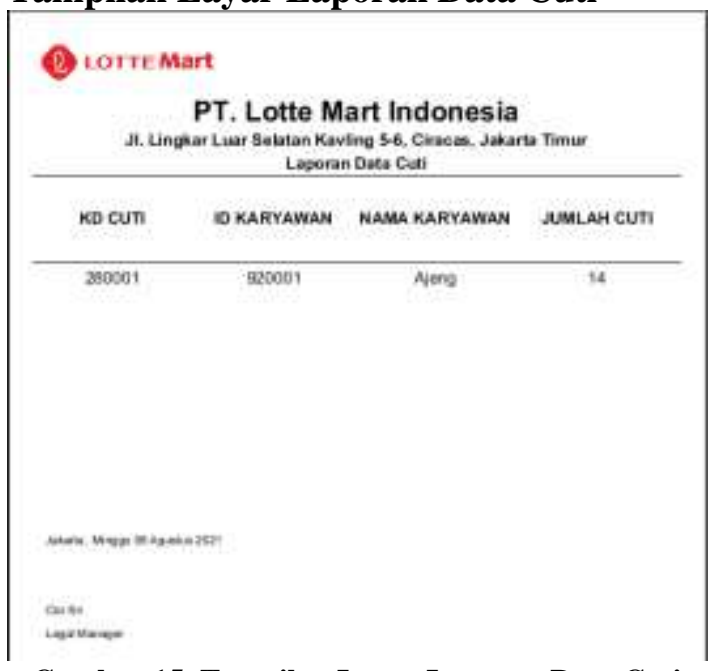

Gambar 15. Tampilan Layar Laporan Data Cuti

Pada tampilan ini admin memberikan Laporan Data Cuti kepada atasan atau HRD. Laporan ini dapat memberikan informasi berupa jumlah cuti yang tersisa serta dapat dilakukan percetakan baik cetak harian ataupun bulanan.

\section{Tampilan Layar Laporan Pengajuan Cuti}

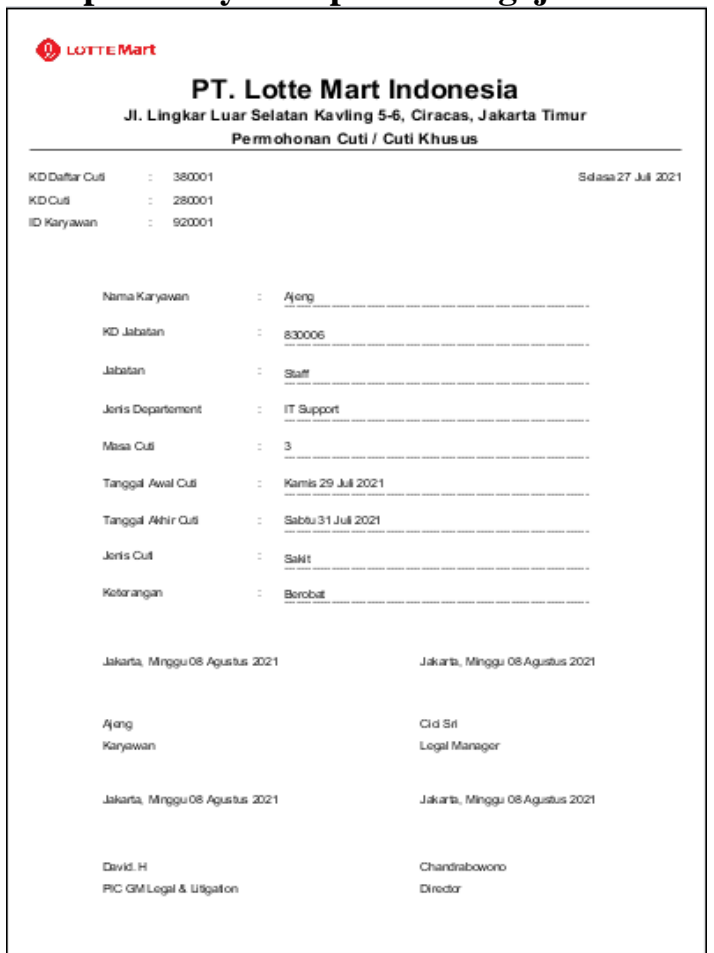

Gambar 16. Tampilan Layara Laporan Pengajuan Cuti
Tampilan ini adalah laporan pengajuan cuti yang dapat mencetak pengajuan cuti. Admin memberikan laporan ini kepada atasan atau HRD untuk di tanda tangani jika atasan dan HRD setuju, jika atasan dan HRD tidak setujui maka tidak ditanda tangani.

Tampilan Layar Laporan Data Admin

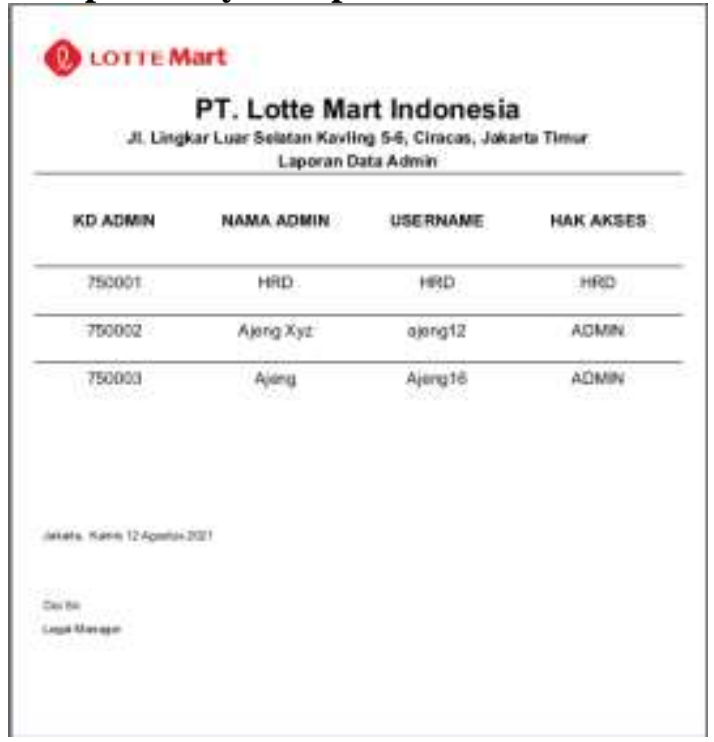

Gambar 17. Tampilan Layar Laporan Data Admin

Pada tampilan ini adalah laporan data admin yang telah tersimpan dan dapat mencetak data admin. Setelah itu laporan ini dapat diberikan ke atasan atau HRD.

\section{SIMPULAN DAN SARAN}

Berdasarkan hasil pembahasan dan penelitian mengenai Perancangan Sistem Informasi Cuti Karyawan Berbasis Java Netbeans pada PT Lotte Mart Indonesia dapat diambil kesimpulan bahwa sebagai berikut:

Selama ini PT Lotte Mart Indonesia masih menggunakan sistem manual, sehingga memperlambat dalam pembuatan laporan cuti karyawan. Dengan menggunakan sistem yang telah terkomputerisasi dapat mencegah keterlambatan laporan cuti karyawan. Dirancangnya sistem informasi pengambilan cuti karyawan pada PT Lotte Mart Indonesia untuk mempermudah bagian HRD dalam memberikan laporan ke pimpinan. Aplikasi sistem pengolahan data juga dapat digunakan untuk membantu mengurangi tingkat kesalahan yang biasanya terjadi dalam sistem manual. 
Untuk meningkatkan atau memaksimalkan Perancangan Sistem Informasi Cuti Karyawan Berbasis Java Netbeans pada PT Lotte Mart Indonesia pada penelitian ini saran yang dapat digunakan sebagai bahan pertimbangannya adalah sebagai berikut:

Sistem informasi pengambilan cuti karyawan pada PT Lotte Mart Indonesia dapat dikembangankan lagi agar dapat terintegrasi dengan perusahaan, Diharapkan adanya pengembangan lebih lanjut dari sistem yang dibuat sebelumnya, sehinga menjadi sistem informasi yang lebih baik dalam mengolah data yang lebih besar dan lebih komplek dimasa yang akan datang, dan untuk meningkatkan pengetahuan dan keterampilan serta kreativitas dalam menjalankan sistem yang membutuhkan pelatihan agar terbiasa dengan sistem tersebut.

\section{UCAPAN TERIMAKASIH}

Peneliti mengucapkan terima kasih kepada Ibu Ulfa Pauziah, M.Kom selaku Dosen Pembimbing Materi, Ibu Maria Cleopatra, S.Kom., M.Pd selaku Pembimbing Teknik, Ibu Mei Lestari, M.Kom selaku Ketua Program Studi Informatika, Ibu Cici Sri Sukiswanti, S.H selaku Manager yang telah memberi kesempatan untuk menganalisa dan menjadikan objek tempat penelitian saya sehingga tugas akhir saya bisa diselesaikan pada perusahaannya. Terima kasih pula kepada kedua orang tua saya yang selalu memberikan semangat dan doa yang tiada henti untuk saya, dan terima kasih kepada semua untuk waktu dan tempat yang telah ikut terlibat penelitian di dalam tugas akhir saya.

\section{DAFTAR PUSTAKA}

Bay Haqi. 2019. Aplikasi Absensi Dosen Dengan Java dan Smarphone. PT. Elex Media Komputindo.

Djatmika, Sastra. 1990. Hukum Kepegawaian di Indonesia. 8 ed. Jakarta: Djambatan.

Elfi Husda, Nur, dan Yvonne Wangdra. 2016. "Pengantar Teknologi Informasi." vi+194.

Jogiyanto, H. .. 2005. Analisa dan Desain Aplikasi: Pendekatan Teori Dan Praktek Aplikasi Bisnis. Andi Offset.

Muslihudin, dan Oktafianto. 2016. “"Analisis dan Perancangan Sistem Informasi Menggunakan Model Terstruktur dan UML'.Yogyakarta: CV. Andi Offset."
Journal of Chemical Information and Modeling 53(9).

Putra, Nusa. 2017. Research \& Development Penelitian dan Pengembangan: Suatu Pengantar. Vol. 4.

Rosa, A. .., dan Salahudin M. 2013. "Rekayasa Perangkat Lunak Terstruktur." in Informatika.

Sugiyono, Prof. Dr. 2016. metode penelitian kuantitatif, kualitatif,dan $R \& D$.

Sutarman. 2021. Buku pengantar Teknologi Informasi.

Syifaun Nafisah. 2003. "Grafika Komputer." Hal. 290 in Yogyakarta: Graha Ilmu. 